\title{
A Gestão de Compras Públicas: um Estudo de Caso da Central de Compras do Distrito Federal
}

\section{Public Procurement Management: a Case Study of the Federal District Purchase Center}

\author{
Grice Barbosa Pinto de Araújo \\ Instituto de Direito Público - IDP - Brasília/Distrito Federal - Brasil \\ gricebp@gmail.com \\ ORCID: 0000-0002-0079-2437 \\ Leany Barreiro de Sousa Lemos \\ Instituto de Direito Público - IDP - Brasília/Distrito Federal - Brasil \\ leanylemos@gmail.com \\ ORCID: 0000-0002-7662-8019
}

Submetido em 16/03/2020; Aprovado em 09/05/2020.

\section{Resumo:}

Objetivo: 0 presente artigo se propõe a analisar, teórica e empiricamente, o modelo de compras adotado pelo governo do Distrito Federal (GDF), no período que compreende 2000-2017. A questão de pesquisa que norteia o presente estudo é a seguinte: a administração pública do Distrito Federal adota um modelo centralizado ou descentralizado de compras públicas? Metodologia: A metodologia adotada baseou-se em um estudo de caso e na coleta de dados primários em sistemas institucionais, complementada por pesquisa bibliográfica e documental. Resultados: Os resultados da pesquisa evidenciam que o modelo de compras praticado pela Administração Pública do Distrito Federal é um modelo de compras parcialmente centralizado, mas que possui características de descentralização. Observou-se que a falta de um sistema institucional que atenda às demandas, implica que os órgãos usem dois ou três sistemas diferentes. Ressalta-se que tal diversificação no uso de sistemas de compras acarreta custos de transparência e consolidação dos dados que são licitados no DF, dificultando a tomada de decisão e implantação de melhorias em todo o ciclo de compras. Implicações Práticas e Teóricas: 0 artigo visa a contribuir teórica e empiricamente com o conhecimento produzido sobre os modelos de compras adotados pelos governos subnacionais brasileiros.

Palavras-chave: Compras públicas; Gestão de compras; Centralização; Descentralização; Central de compras e contratações.

\begin{abstract}
:
Objective: This article proposes to analyze, theoretically and empirically, the purchasing model adopted by the Federal Government of the Federal District (GDF), with no period comprising 2000-2017. The research question in North America or in the present study is the following: does the Federal District public administration adopt a centralized or decentralized model of public procurement? Method: An adopted methodology was based on a case study and on the collection of primary data in institutional systems, complemented by bibliographic and documentary research. Results: The research results show the purchasing model practiced by the Federal District Public Administration and a centralized closed purchasing model, but with decentralization characteristics. To note that an institutional system that meets the demand is missing, implies that the agencies use two or three different systems. It is noteworthy that such diversification does not use purchasing systems with coverage costs and reduces the data that are bid on in the DF, making it difficult to make decisions and implement improvements throughout the purchasing cycle. Practical and Theoretical Implications: The article aims to contribute theoretically and empirically with the knowledge produced on the purchasing models adopted by the Brazilian subnational governments.
\end{abstract}

Keywords: Public procurement; Procurement management; Centralization; Decentralization; Center of procurement and contracts. 


\section{Introdução}

As compras públicas devem garantir ao governo o suprimento de bens ou a prestação de serviços necessários ao seu funcionamento, e o uso estratégico da demanda governamental pode aperfeiçoar o desempenho do governo nas ações sob sua responsabilidade e garantir mais rapidez na consecução de determinados projetos, com melhoria da qualidade do serviço público.

0 presente artigo se propõe a analisar, teórica e empiricamente, o modelo de compras adotado pela Secretaria de Planejamento, Orçamento e Gestão do Distrito Federal (SEPLAG), que é órgão normativo e centralizador de compras do governo do Distrito Federal (GDF), no período que compreende 2000-2017. Trata-se, portanto, de um estudo longitudinal que almeja analisar o modelo de compras adotado no âmbito da administração pública local.

Para tanto, a questão de pesquisa que norteia o presente estudo é a seguinte: a administração pública do Distrito Federal adota um modelo centralizado ou descentralizado de compras públicas? A investigação deste problema de pesquisa visa a contribuir tanto do ponto de vista teórico, quanto empírico com a área de estudos de compras e aquisições governamentais, almejando fornecer elementos para a compreensão do processo de compras, assim como a racionalidade, eficiência e sustentabilidade dos gastos públicos.

Operacionalmente, foi realizada uma ampla e densa pesquisa bibliográfica sobre o tema. A coleta de dados primários envolveu o Portal da Transparência do Distrito Federal, o Sistema de Compras Eletrônicas (e-Compras) e o Sistema Integrado de Gestão Governamental (SIGGO). Destas fontes, extraíram-se uma planilha com aproximadamente 12 mil registros do e-Compras; e 9 planilhas, com uma média de 16 mil registros por planilha, do SIGGO.

Complementando essa base de dados, também foi necessário levantar o valor autorizado de compras das atas de registros de preços, no período de 2009 a 2017, o qual só foi possível mediante extração de dados do Business Inteligent (BI), ferramenta de tecnologia da informação, disponível no âmbito da SEPLAG do Distrito Federal.

A pesquisa também se vale de dados primários obtidos, por meio de um questionário, contendo 93 perguntas, aplicado em 2016 a todos os órgãos da Administração Pública local, pela Subsecretaria de Compras Governamentais, responsável pela Central de Compras, que buscou identificar o atual cenário em que as compras se encontram. 0 questionário foi encaminhado a todos os 85 órgãos que compõe a Administração Pública do Distrito Federal para que os gestores/responsáveis pela área de compras de cada órgão respondesse. Aos órgãos, foi dada a orientação que respondessem o questionário apenas uma vez, podendo ter suas respostas editadas até a data final de encaminhamento do formulário.

0 artigo está dividido nas seguintes seções, além desta introdução: revisão teórica, apresenta-se e discute-se o referencial teórico que embasa a pesquisa, para tanto, destacam-se as seguintes subseções teóricas: um apanhado da importância das compras públicas; a legislação que regulamenta as compras públicas no país; o binômio centralização vs. descentralização de compras; e, por fim, o caso das compras públicas no Distrito Federal. Na sequência, apresenta-se a metodologia de pesquisa. Na terceira seção, são apresentados e problematizados os resultados da pesquisa, analisando o modelo de compras públicas praticado no governo do Distrito Federal. Por fim, são tecidas algumas considerações finais.

\section{Revisão Teórica}

\subsection{Compras Públicas}

A importância das compras públicas pode ser percebida sob diferentes vieses e matizes, a começar pelo fato de que elas estão entre as principais atividades econômicas de um governo, possuindo um papel fundamental na estruturação de recursos para viabilizar as políticas públicas (Thai, 2001 apud Zylberman, 2015).

Ademais, as compras públicas também possuem uma importância seminal no processo de desenvolvimento dos mercados (Bleda \& Chicot, 2020), visto que constituem o braço comercial dos governos para a contratação de bens e serviços cujo objetivo é conceder a provisão necessária para que o setor público desempenhe suas atividades e responsabilidades mais precípuas (Harland et al, 2019).

Conforme destacam Ribeiro e Inácio Júnior (2019), a relevância das compras públicas é realçada internacionalmente uma vez que a Organização Mundial do Comércio (OMC) possui o Acordo sobre Contratação Pública (GPA - Agreement on Government Procurement) que visa a abrir o mercado de 
compras governamentais e garantir a não discriminação de fornecedores.

A centralidade do debate das compras públicas é principalmente verificada no que se refere à racionalidade e eficiência no uso do erário público. Segundo a Organização para a Cooperação e Desenvolvimento Econômico (OCDE, 2016), tendo em vista a quantidade de recursos financeiros dedicados às aquisições governamentais, alcançar ganhos de eficiência é crucial para gerar espaço fiscal adicional, o que se traduz em maior capacidade para implementar políticas públicas.

De acordo com Raposo et al (2016), o novo paradigma das compras públicas é aliar a eficiência ao uso do poder de compras do Estado, traduzindo como eficiência comprar melhor pelo menor custo para a efetivação das políticas, de tal forma, que as análises realizadas durante os processos de compras assegurem a garantia, além de eficiência, de que os resultados obtidos sejam os melhores.

Tridapalli (2008) verificou que entre os 26 estados brasileiros mais o Distrito Federal, 10 já possuíam um sistema de compras que funcionava como um sistema integrado para atender toda a cadeia de suprimento, isto é, desde as requisições, passando pelo processo de compras até o controle de estoque dentro dos órgãos governamentais.

No que concerne à integração dos sistemas de estoques ao processo de compras, a pesquisa demonstrou uma grande deficiência dos sistemas brasileiros, naquela época. Esta integração faz-se necessária para permitir uma melhor gestão das requisições com identificação de forma automática do ponto de pedido de grande parte dos itens comprados pelo estado. E apenas dois estados executavam esta funcionalidade, muito embora não o fizessem em sua integralidade. Estes estados eram Amazonas e Distrito Federal (Tridapalli, 2008).

De acordo com Ferrer (2015), a implantação de sistemas eletrônicos de compras também pode ser um problema ao abarcarem principalmente a fase externa do processo de compras, o qual é mais do que isso, demandando a compreensão do processo como um todo.

Conforme assevera Tridapalli, Fernandes e Machado (2011), a grande maioria das unidades governamentais não utiliza técnicas adequadas de planejamento alinhadas com o plano estratégico, o desenvolvimento de fornecedores, o processo virtual, a gestão de estoques e a gestão estratégica. Os autores enfatizam que a melhoria da qualidade dos gastos passa, necessariamente, pela modernização da cadeia de suprimentos. A estratégia de modernização da cadeia de suprimento deve ser integrada à estratégia de cada unidade de governo para não ficar divergente dos objetivos gerais e, com isto, ficar sem o apoio político para execução das mudanças necessárias.

Batista e Maldonado (2008, p. 683) ressaltam que há um aparente paradoxo na execução das compras públicas, uma vez que, em âmbito governamental, ainda se pode notar a presença de "estruturas tradicionais, funcionais e departamentadas", cuja capacidade decisória é débil e engessada, o que se contrapõe, frontalmente, a um processo de aquisição que vem exigindo cada vez mais dinamicidade e flexibilidade.

\subsection{Legislação de Compras no Brasil}

No Brasil, a lei que rege as compras é a Lei no 8.666/93, também conhecida como Lei de Licitações e Contratos Administrativos, que segundo Miguel (2015) é fruto da junção de outras legislações, como o Código de Contabilidade Pública (Decreto no 4.536/22), o Decreto-Lei no 200/67 e o Decreto-Lei no 2.300/86. Entretanto, segundo o autor, o momento peculiar que passava o Brasil na época da promulgação desta lei, assolado por uma crise política, econômica e sérios problemas de corrupção, foi a tônica da legislação que, por sua vez, cerceia de maneira extensa atuações discricionárias do administrador público, atingindo gestores em todos o país e muitas vezes tendo efeitos adversos nos resultados.

A Lei de Licitações estabelece normas gerais sobre licitações e contratos administrativos pertinentes a obras, serviços, compras, alienações e locações no âmbito da Administração Pública Direta e Indireta da União, dos Estados, do Distrito Federal e dos municípios.

A realização do procedimento licitatório, nos termos do que dispõe o Art. $3^{\circ}$ da Lei no 8.666/93, serve a três finalidades fundamentais: 1) buscar a melhor proposta, estimulando a competitividade entre os potenciais contratados, a fim de atingir o negócio mais vantajoso para a Administração; 2) oferecer iguais condições a todos que queiram contratar com a Administração; e, 3) promover o desenvolvimento nacional sustentável, gerando, em nome da isonomia, a possibilidade de participação no certame licitatório de quaisquer interessados que preencham as condições previamente fixadas no 
instrumento convocatório.

A licitação fixa quatro procedimentos para a seleção da proposta mais vantajosa, conforme dispõe os arts. 45 e 46, da Lei 8.666/93. São eles: 1) menor preço (que é o mais comum); 2) melhor técnica; 3) técnica e preço; e 4) maior lance ou oferta. Estas modalidades de licitação definem o grau de concorrência e o rito a ser observado nos processos licitatórios. As modalidades compreendem: concorrência, tomada de preços, convite, concurso e leilão.

Ao longo de 25 anos de vigência, a Lei de Licitações passou por inúmeras alterações com intuito de torná-la mais adequada aos fins para os quais se propõe. Neste contexto, conforme expõe Delzot e Barbosa (2017), foram 61 Medidas Provisórias e 19 leis, totalizando 80 normas, as quais buscaram melhorias no atendimento das necessidades das políticas públicas e de seus beneficiários.

Dentre as mais relevantes, destaca-se a instituição de uma nova modalidade de licitação, denominada pregão, por meio da Lei no 10.520/2002. Esta modalidade veio para dar maior celeridade e simplificação dos processos, já que ocorre em sessão pública como um leilão reverso. Ele pode ser utilizado apenas para aquisição de bens e serviços comuns.

Com isso, criou-se o ambiente propício para o aprimoramento e difusão do Sistema de Registro de Preços (SRP), definida pelo art. 15 da Lei Federal no 8.666, de 21 de junho de 1993 e regulamentada no âmbito Federal pelo Decreto no 7.892, de 23 de janeiro de 2013, permitindo a redução da burocracia e os elevados custos de transação nas contratações. Tal prática tornou o Brasil, segundo Ferrer (2013), um dos países mais avançados no mundo no que se refere à inovação em compras públicas.

Segundo Raposo et. al. (2016), o SRP apresenta uma série de vantagens, a saber: possibilita uma maior agilidade no processo de contratações; melhor gerenciamento e controle de estoques; melhor execução orçamentária, com consequente redução de custos; redução do número de processos licitatórios; melhor poder de compras de bens e serviços; padronização dos bens e serviços comuns, possibilitando a participação conjunta dos órgãos e entidades que têm a mesma demanda, visto que sua principal atuação é poder atender a mais de um órgão que planeja comprar os mesmos itens.

\subsection{Centralização versus Descentralização das Compras Públicas}

Outro tema relevante é sobre modelo centralizado vs. descentralizado de compras. Fernandes (2015) afirma que as compras descentralizadas são "aquelas realizadas de forma autônoma pelos próprios órgãos ou entidades da Administração que serão usuários dos mesmos", em contrapartida, as compras centralizadas seriam "aquelas realizadas em uma unidade designada pela administração para tal finalidade", por exemplo, uma central de compras encarregada de executar todas as aquisições do Estado.

Segundo Silva (2016), a centralização permite uniformização de ações e adoção de um procedimento padrão para todas as compras, como também um atendimento mais eficiente em caso de falta de algum item em qualquer unidade. Este modelo também apresenta uma melhor gestão dos estoques, com maior eficiência no controle.

Conforme nota Silva (2016), parte da literatura especializada sugere a combinação de ambos modelos ao observar que determinados benefícios de um modelo remetem a uma deficiência de outro, ou seja, um sistema híbrido que permite maximizar as qualidades e atenuar os defeitos de cada modelo. Os formatos que combinem a centralização e descentralização em múltiplos e diversificados arranjos, deverão estar apoiados na utilização intensiva das tecnologias de informação e comunicação eletrônica.

Para Tridapalli et. al. (2011), a grande discussão das compras governamentais é como conseguir o melhor preço, com estimulação da competição e a eliminação da corrupção. Os autores afirmam que a centralização é mais eficiente como efetivação de processos de compras para o Sistema de Registro de Preços, pois permite agregar várias demandas em um único processo.

Assim, Cartaxo e Marini (2010) evidenciaram que alguns estados brasileiros institucionalizaram, a partir da década de 2000, as centrais de compras (SP, RJ, BA, CE, MG, SC, PE, RS, RN, PR, PI), visando a possibilidade de reduzir os preços pela economia de escala, monitorar e controlar mais facilmente os processos e padronizar os itens adquiridos.

Os autores inferem ainda que a própria gestão dos portais eletrônicos e sistemas informatizados de compras levou os Estados a optarem por centralizar, em maior ou menor grau, pelo menos parte dos processos de suas compras em um órgão gerenciador.

A estrutura centralizada de compras, segundo Moreira e Ribeiro (2016) apud Silva (2016), 
justifica-se naquelas situações em que os mesmos materiais são adquiridos por várias unidades, visto que a centralização permite obtenção de melhores preços, custos, qualidade, centralizando as tomadas de decisões relativas à especificação do produto e aos procedimentos da contratação.

\subsection{As Compras Públicas no Distrito Federal}

No Distrito Federal, a Central de Compras foi instituída em 1999. As primeiras competências da Subsecretaria de Compras e Licitações (SUCL) foram estabelecidas em 2002 e estão dispostas na Portaria no 563, de 5 de setembro de 2002, que alterou o anexo único da Portaria no 648, de 21 de dezembro de 2001, a qual aprovou o regimento geral da Secretaria de Fazenda e Planejamento.

Em 2005, por meio do Decreto no 25.966, a SUCL foi dotada do Sistema de Controle e Acompanhamento de Compras e Licitações e Registro de Preços do Distrito Federal (e-Compras), visando a garantir um mecanismo adequado e eficiente no trato das informações relativas a compras e licitações de materiais e serviços adquiridos pelo GDF. Concebido para atender a todas as unidades do complexo administrativo distrital, o sistema automatizou integralmente o fluxo do processo licitatório.

A partir de 2006, foram verificadas duas alterações de estrutura. A primeira se deu por intermédio do Decreto no 27.607, de 05 de janeiro de 2007, e, no documento, a Central passou a integrar a Secretaria de Planejamento e Gestão, denominando-se Subsecretaria de Suprimentos; ao passo que a segunda alteração veio com o Decreto no 33.243 , de 04 de outubro de 2011, quando passou a denominar-se Subsecretaria de Licitações e Compras.

Em 2015, a Central de Compras e Licitações estava na estrutura da Secretaria de Estado de Gestão Administrativa (SEGAD), com a denominação na estrutura de Subsecretaria de Licitações (SULIC). Com o Decreto ${ }^{\circ}$ 36.825, a SEPLAG absorveu todas as competências da SEGAD, sem deixar de lado a função de órgão central de planejamento do governo, além do estudo e monitoramento das políticas públicas governamentais e da gestão estratégica e de projetos. Segundo o Relatório de Atividades da SEPLAG, ainda em 2015, investiu-se na elaboração de um novo modelo de compras com a edição dos Decretos $\mathrm{n}^{\mathrm{o}}$ 36.519 e 36.520 que previam a centralização, padronização e planejamento das compras e licitações (SEPLAG, 2015).

Já em 2016, os Decretos no 37.280 e 37.484 alteram a designação da SULIC para Subsecretaria de Compras Governamentais (SCG) e sua estrutura administrativa, respectivamente. Ainda em 2016, a Secretaria de Planejamento, Orçamento e Gestão editou o Decreto no 37.729, de 26 de outubro de 2016, instituindo o Programa de Gestão de Compras Governamentais (ComprasDF), aplicável às aquisições e à contratação de serviços. 0 objetivo foi contribuir para gestão da despesa, visando a reduzir os custos e melhorar a qualidade dos gastos nas compras públicas; padronizar e racionalizar as compras governamentais; além de garantir mais transparência e participação da sociedade; e ampliar a participação das microempresas, das empresas de pequeno porte e dos microempreendedores individuais.

Em 2019, com a mudança da gestão governamental, a estrutura da Central de Compras foi remanejada. Segundo o Decreto no 39.610, de 1 de janeiro de 2019, a Secretaria de Estado de Planejamento, Orçamento e Gestão do Distrito Federal passa a integrar a Secretaria de Estado de Fazenda do Distrito Federal, alterando sua denominação para Secretaria de Estado de Fazenda, Planejamento, Orçamento e Gestão do Distrito Federal e, posteriormente, para a Secretaria de Economia. Com essa alteração de dirigentes a estrutura anterior foi alterada causando, incialmente, uma descontinuidade dos projetos.

Como se nota, pode-se afirmar que a trajetória institucional da Central de Compras do DF passou por alterações e modificações desde sua criação no final dos anos 1990. Tais modificações relacionam-se tanto à sua nomenclatura quanto às atribuições. Como já anunciado anteriormente, este trabalho intenta analisar, teórica e empiricamente, o modelo adotado pela Secretaria de Planejamento, Orçamento e Gestão do Distrito Federal (SEPLAG), que foi órgão normativo e centralizador de compras do Governo do Distrito Federal (GDF), no período 2000-2017.

Pelo exposto até aqui, descreveu-se desde o quadro geral das compras públicas, passando pela legislação e pelo binômio centralização-descentralização, até culminar na situação específica que esta pesquisa se encarrega, que é o modelo de compras da administração pública local. Diante deste panorama evidenciado, ressalta-se que a gestão estratégica das compras é importante para a administração pública, pois, segundo Ferrer (2013, p. 145), inesperadas alterações no arcabouço 
jurídico podem ocorrer, necessitando-se da consolidação de uma "inteligência centralizada de compras", que permita uma visão única do processo.

Acredita-se que parte da falta de informações e controle ocorrem porque não se promove uma visão integrada do processo de gestão de suprimentos e das compras em si. A descentralização sem controle eletrônico leva a compras repetidas, redundância de estruturas e procedimentos, desperdícios nos estoques, que desencadeiam mau uso dos recursos públicos.

Todavia, a centralização absoluta das compras em larga escala possui uma série de dificuldades para implantação, como Fiuza e Medeiros (2013) retrataram, tais como: excessiva demanda concentrada, risco de lentidão nos processos licitatórios, redução da autonomia administrativa, distanciamento dos demandantes das compras e atrasos na entrega, repercutindo em toda a Administração.

A escolha de um determinado modelo, segundo aponta Silva (2016), sugere a combinação entre os modelos centralizados e descentralizados, ao observar que determinados benefícios de um modelo remetem a uma deficiência de outro, ou seja, um sistema híbrido que permite maximizar as qualidades e atenuar os defeitos dos modelos.

\section{Metodologia}

A pesquisa alicerça-se na taxionomia apresentada por Vergara (2008), permitindo qualificá-la, inicialmente, em relação a dois aspectos: quanto aos fins e quanto aos meios de investigação. Quanto aos fins, a pesquisa caracteriza-se como descritiva, detalhando o modelo de compras do GDF e suas características operacionais. Quanto aos meios, ela é bibliográfica, documental e data-driven, porque tem sua fundamentação teórico-metodológica baseada na literatura existente, bem como vale-se de normas e regramentos emitidos pelo GDF e pelo uso de dados primários de sistemas disponíveis.

Do ponto de vista do recorte temporal, a pesquisa compreende o período 2000-2017. Este espaço de tempo foi selecionado porque contempla uma fase em que a administração pública local implantou um modelo estruturado de compras, que preconizou, em um primeiro momento, a Central de Compras do DF e, posteriormente, a criação de sistemas eletrônicos de compras, tais como: o e-Compras e o ComprasDF.

O problema de pesquisa que este estudo intenta investigar é se a administração pública do Distrito Federal adota um modelo centralizado ou descentralizado de compras públicas. Opta-se por investigar o binômio centralização vs. descentralização do modelo de compras públicas do Distrito Federal com o objetivo precípuo de averiguar a efetividade da central de compras implementada no DF, assim como os sistemas eletrônicos posteriormente instituídos com vistas à informatização das compras públicas locais.

A coleta de dados dá-se por meio do Portal da Transparência do Distrito Federal, que converge dados do Sistema de Compras Eletrônicas (e-Compras) e do Sistema Integrado de Gestão Governamental (SIGGO). Destas fontes, extrai-se uma planilha com aproximadamente 12 mil registros do e-Compras; e 9 planilhas, com uma média de 16 mil registros por planilha, do SIGGO. Ou seja, é construída uma base de dados com mais de 100 mil registros.

Para se obter as informações do e-Compras via Portal de Transparência, é necessária a exportação dos dados relativos às licitações realizadas entre os anos de 2005 a 2017, nesta ferramenta. A consolidação dos dados dos procedimentos licitatórios é feita conforme sua situação - adjudicado, finalizado, homologado, homologado parcial e homologado total.

No que concerne às informações extraídas do SIGGO, também via Portal, foram exportados dados relativos a valores empenhados, liquidados e pagos pelos órgãos do DF para o Grupo de Natureza da Despesa (GND) de "outras despesas correntes no elemento de despesa" e "outros serviços de terceiros pessoa jurídica, material de consumo e material de distribuição gratuita".

Importante destacar que existem, no Distrito Federal, vários sistemas que comtemplam as informações pertinentes ao ciclo de compras. Além do e-Compras e do SIGGO, há também o Sistema de Gestão de Materiais (Sigma.Net) e o Sistema de Gestão de Patrimônio (SiGespat). Porém, nenhum deles possui integração, causando, assim, duplicidades de lançamentos, inconsistência de dados, o que impossibilita uma análise integrada das informações.

Os dados primários coletados são referentes aos anos de 2009 a 2017. Após a estruturação das planilhas, os órgãos são classificados em Secretarias de Estado, Administrações Regionais, Entidades e 
Órgãos Especializados, de acordo com a estrutura governamental descrita no Portal do Governo do Distrito Federal.

Para construção da análise, são necessários também os dados referentes aos valores autorizados de compras das atas de registros de preços, no período de 2009 a 2017, extraídos da ferramenta de Business Intelligent (BI) da SEPLAG do Distrito Federal.

Por fim, o diagnóstico do ciclo de compras é realizado por iniciativa do próprio GDF em pesquisa junto aos órgãos setoriais, com vistas a levantar informações para o sucesso da modernização do seu ciclo de compras. 0 questionário foi aplicado no segundo semestre de 2016 e continha 93 perguntas, tanto de natureza objetiva quanto subjetiva. A intenção era mapear aspectos relacionados ao planejamento de compras, aos procedimentos para licitação, fases e prazos, à participação no sistema de registro de preços, à contratação de serviços e de material de consumo e permanente, além da gestão de contratos. Entre as perguntas do questionário que subsidiaram diretamente este estudo, destacamse as seguintes: i) o órgão/entidade possui planejamento anual de compras?; ii) quem realiza a licitação?; iii) se possui autonomia para licitar, informe o no do Decreto Distrital que concede essa autonomia para o órgão/entidade; iv) qual(is) sistema(s) eletrônico(s) seu órgão/entidade utiliza para realizar as licitações?; v) o órgão/entidade é participante de licitação do Sistema do Registro de Preços no Distrito Federal?

\section{Resultados e Discussões}

\subsection{As Compras Públicas no Distrito Federal: Modalidades de Licitação e Valores}

De acordo com dados dos Relatórios de Atividades relativos ao período 2000-2005, no que se refere ao volume de procedimentos licitatórios realizados pela Central de Compras do Distrito Federal, verificou-se um crescimento de $70,83 \%$, saindo de 856 procedimentos no ano de 2000 para 2.800 em 2005.

Verifica-se, portanto, que, nos primeiros anos da central de compras, houve uma clara tendência pela centralização das aquisições do poder público local. A inclusão da Secretaria de Saúde, em 2002, e a implementação de uma nova forma de licitar por meio do pregão, em 2003, foram fatores impulsionadores deste crescimento.

Verifica-se que, nos primeiros três anos da Central de Compras, as modalidades mais usuais foram convite, concorrência e tomada de preços, que abarcavam a grande maioria do valor licitado, algo em torno de $90 \%$, entre 2000 e 2002.

Já a partir de 2003, percebe-se um redirecionamento destas licitações para a modalidade pregão, implementada naquele ano conforme exposto anteriormente. 0 sucesso desta modalidade foi instantâneo, conforme demonstra o Gráfico 1.

Gráfico 1. Valor das Aquisições em Reais (R\$), 2000-2005

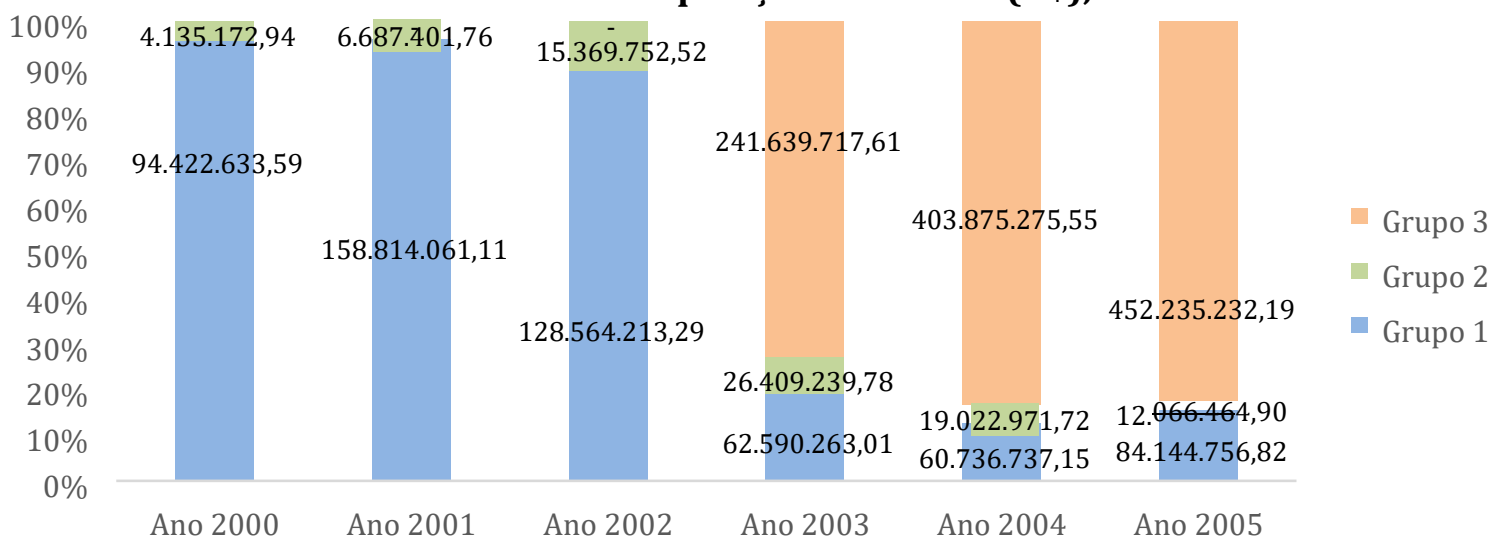

\section{LEGENDA:}

Grupo 1: valores relativos a concorrência, tomada de preços e convites; Grupo 2: valores relativos a dispensas e inexigibilidades; Grupo 3: valores relativos a pregão e pregão por SRP.

Fonte: Elaborado pela autora com base nos Relatórios de Atividades da SEPLAG, período 2000-2005.

O pregão passou a concentrar, em média, 80\% dos procedimentos entre 2003-2005. Diante de um 
crescente aumento da demanda e dos valores envolvidos nas aquisições, no ano de 2004, iniciou-se o projeto de informatização de compras com o desenvolvimento do sistema de controle e acompanhamento de compras e licitações e registro de preços, composto por módulos que vão desde o catálogo de materiais, serviços e banco de preços, passando pela requisição inicial até o processamento da licitação, inclusive a sua homologação.

Este projeto de informatização de compras resultou na implantação do sistema e-Compras, em 2005. Até o mês de outubro de 2017, foram realizados 11.442 procedimentos licitatórios por meio do eCompras, a partir dos quais foi possível traçar um perfil das compras, observando-se além do número de procedimentos, o total de recursos pagos em cada modalidade. É válido ressaltar que mesmo com a utilização do sistema e-Compras, muitos outros órgãos ainda continuaram a utilizar os mais diversos sistemas de compras disponíveis no mercado, quando não encaminhavam suas demandas ao órgão central, o que ainda mantinham as informações dispersas e descentralizadas.

Com relação ao número de procedimentos, todos foram contabilizados independentemente da situação da licitação, tendo em vista que exigiram dispêndio de tempo e realização de procedimentos administrativos. Até 2010, as licitações realizadas no sistema e-Compras para aquisição de material eram levadas a cabo por intermédio das modalidades convite, concorrência, tomada de preços, dispensa e pregão eletrônico. Este último, que representava em média $81 \%$ dos procedimentos entre 2005-2010, passou a ser utilizado em $100 \%$ das licitações a partir de 2011.

Ressalta-se que não existia centralização dos procedimentos nem das informações, mesmo com o sistema em utilização pelo órgão central. Consequentemente ocorria também a descentralização da gestão da informação, ou seja, quando se analisa as informações de pagamento no sistema SIGGO, verifica-se que havia muito mais licitações do que estava cadastrado no sistema da Central de Compras. Em suma, não havia centralização da informação, tampouco da gestão destas informações.

No que se refere ao quantitativo total de licitações, dois fatos chamam a atenção para esse período: primeiro, o número elevado de licitações de materiais entre os anos 2006 a 2010, representando maior capilaridade da Central de Compras junto aos seus órgãos integrantes; e, em segundo lugar, a tendência oposta, verificada por meio do expressivo decréscimo no quantitativo de licitações a partir de 2011.

Ressalta-se que, em 2011, órgãos que utilizavam o sistema, como a Companhia Energética de Brasília (CEB), a Companhia de Saneamento Ambiental do Distrito Federal (CAESB) e o Metrô do Distrito Federal, deixaram de usar o sistema e-Compras, em virtude de inconsistências e falhas sistêmicas, migrando para sistemas federais. Adicione-se a isso o fato de que a própria Central de Compras começou a utilizar o sistema do Governo Federal - o ComprasNet - para suas licitações, resultando, assim, no decréscimo do número de procedimentos licitatórios, tal como demonstrado no gráfico 1.

Outra questão relevante encontrada pela Coordenação de Gestão de Suprimentos junto ao Sistema de Normas Jurídicas do Distrito Federal (SINJ-DF) foi o alto grau de descentralização de compras no Distrito Federal. Verificou-se que 43 órgãos da Administração Pública possuíam, em 2017, decretos de descentralização de compras, sendo que algumas secretarias tinham mais de um decreto publicado, caso da Secretaria de Cultura e da Secretaria de Meio Ambiente, que possuem, respectivamente, 7 e 5 decretos publicados acerca de descentralização de compras. Do total de 72 decretos, $53 \%$ destes foram publicados entre 2012 e 2013, indicando, assim, um esvaziamento da Central de Compras do Distrito Federal neste período

Fatores como a troca de governo a partir de 2011, a falta de manutenção corretiva e adaptativa no sistema e-Compras, combinado com uma flexibilidade no aceite das solicitações de descentralização, podem ter contribuído para a redução do volume de procedimentos licitatórios realizados pela Central de Compras.

De acordo com estudo realizado pela Subsecretaria de Licitações (SULIC), constante do Relatório de Atividades SEPLAG (2015), a descentralização das compras do GDF entre 2011-2014 aumentou significativamente o custo médio das contratações, conforme prevê a literatura pertinente. Enquanto em 2011 gastava-se em média menos de $\mathrm{R} \$ 800$ mil, em 2015, este gasto médio ultrapassou $\mathrm{R} \$ 1,2$ milhão, um aumento nada modesto de $50 \%$. Isso significou que a descentralização acarretou um aumento do gasto público ao permitir que os órgãos realizassem suas próprias contratações isoladamente. Outro fator importante diz respeito à utilização de múltiplos sistemas de compras, conforme será evidenciado mais adiante.

É válido destacar que nesse período ocorreram diversas solicitações dos órgãos para realizar suas 
aquisições de forma isolada, as reclamações ressaltavam, sobretudo, a morosidade do sistema de compras centralizado. Deste modo, os gestores à época permitiram que a maioria dos órgãos fossem realizando suas próprias compras autonomamente, o que acarretou no enfraquecimento da subsecretaria responsável pelas compras públicas. Com o advento dos decretos de descentralização, os órgãos também foram buscar sistemas para realizar suas próprias licitações, sendo que o mais utilizado foi o ComprasNet. Isso permitiu efetivamente a pulverização dos procedimentos e das informações.

\subsection{Diagnóstico de Compras no DF por Questionários}

Em 2016, a Secretaria de Planejamento, Orçamento e Gestão, com a edição do Programa de Gestão de Compras Governamentais (ComprasDF), por meio do Decreto no 37729/2016, realizou um diagnóstico e identificou o seguinte cenário:

- Portal de Compras Públicas: desatualizado;

- Sistema Corporativo para Compras: inexistente;

- Metodologia de Compras Pública: inexistente;

- Sistema Normativo de Compras Públicas: desatualizado;

- Trilha de Capacitação: deficiente;

- Sistema Integrado de Almoxarifado: sem manutenção;

- Sistema de Distribuição de Produtos: deficiente;

- Sistema de Indicadores de Desempenho: inexistente.

Foi realizado diagnóstico do ciclo de compras junto aos órgãos setoriais, com o objetivo de levantar informações essenciais para se elaborar um plano de modernização do ciclo de compras do GDF que fosse bem sucedido. 0 questionário foi aplicado no segundo semestre de 2016 e continha 93 perguntas. A orientação foi de que cada órgão respondesse ao questionário apenas uma vez, podendo ter suas respostas editadas até a data final de encaminhamento do formulário. Este trabalho não realiza uma análise exaustiva (na íntegra) de todas as questões do formulário. Para fins analíticos, os assuntos serão agrupados levando-se em consideração aqueles tópicos mais pertinentes à identificação da análise do modelo de compras.

Em 2016, a estrutura de governo do Distrito Federal possuía 85 órgãos, sendo 20 Secretarias de Estado, 31 Administrações Regionais, 28 Entidades e 6 Órgãos Especializados. Cerca de dois terços dos órgãos e entidades que compõem a administração pública distrital participaram do diagnóstico, revelando, assim, que o esforço empreendido pelo governo resultou em uma efetiva participação de sua estrutura administrativa, propiciando informações valiosas para um diagnóstico robusto.

No que diz respeito ao planejamento e execução das compras, verificou-se que mais da metade dos órgãos não os realiza, isso ocorre em maior grau nas Secretarias e Entidades. Com relação ao grau de execução desse planejamento, dois terços dos órgãos responderam que realizaram mais da metade de seu planejamento. 0 gráfico 2 apresenta a frequência da realização do planejamento anual de compras.

Gráfico 2. Órgãos que Realizam Planejamento Anual de Compras (N)

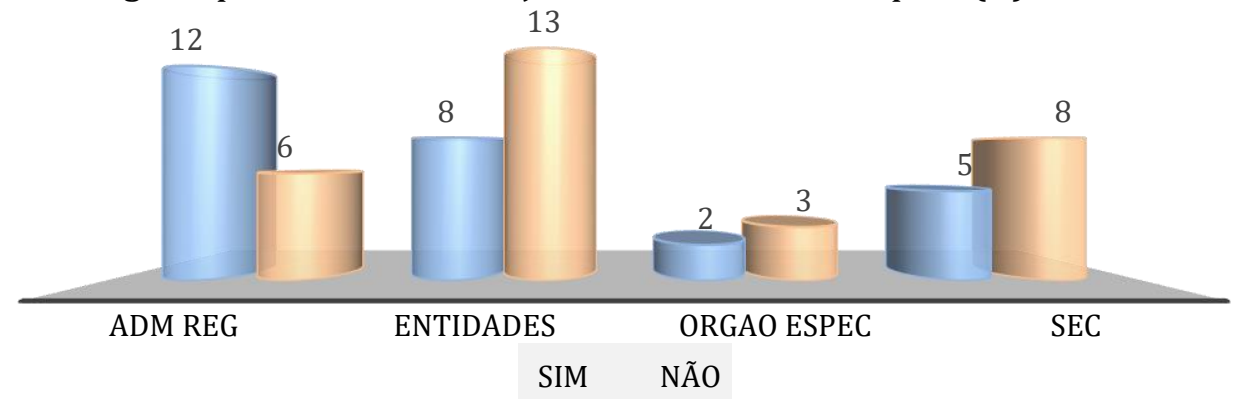

Fonte: Elaboração própria, com base nas planilhas de respostas do diagnóstico - COPLAM/SCG/SEPLAG.

Sobre o modelo usado para as aquisições pelo órgão, uma pequena parte dos respondentes afirmaram que usam o modelo misto de contratação. Entretanto, é bastante paritária a divisão entre os órgãos que realizam suas próprias licitações (47\%) e aqueles que realizam aquisições de forma centralizada na SEPLAG (46\%), como se pode verificar no gráfico 3. Destaca-se que as licitações realizadas no próprio órgão equivalem ao modelo de compras descentralizado, ao passo que o modelo 
misto congrega tanto licitações feitas no órgão centralizador de compras (SEPLAG), quanto nos demais órgãos do GDF.

\section{Gráfico 3. Modelo de Compras, Centralizado x Descentralizado}

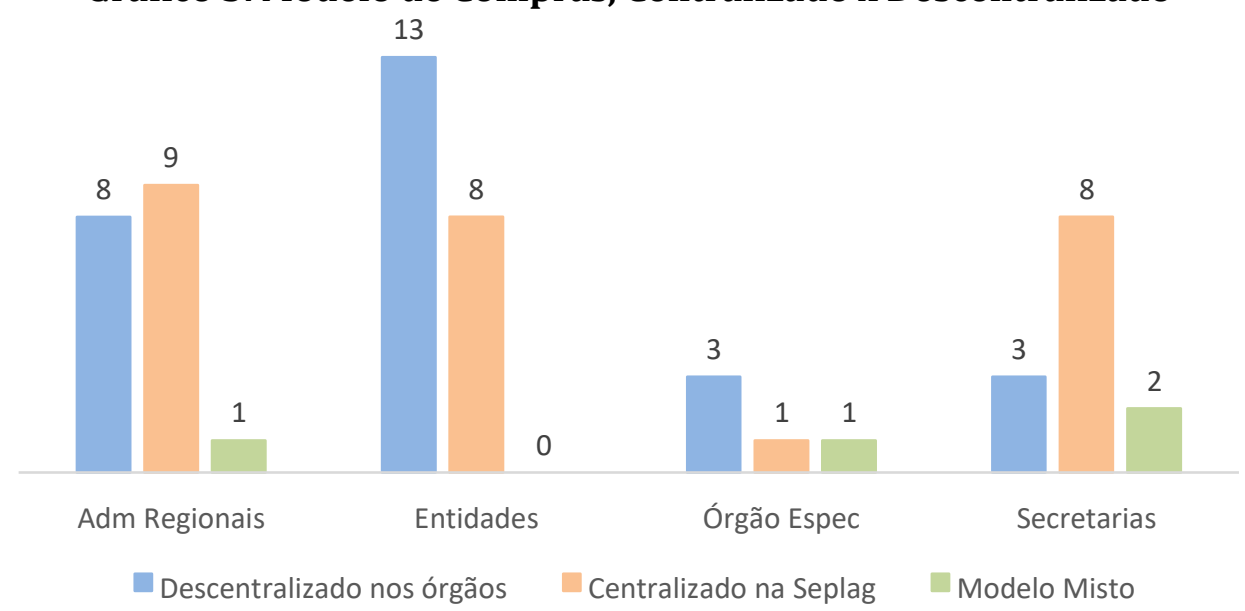

Fonte: Elaborado pela Autora com base nas planilhas de respostas do diagnóstico COPLAM/SCG/SEPLAG.

Os dados do diagnóstico institucional do governo evidenciam, ainda, que mais da metade dos órgãos/entidades não possuem sistema eletrônico para realizar licitações. No período contemplado pela pesquisa, o sistema e-Compras era utilizado apenas pela Central de Compras do DF e pelos órgãos setoriais participantes das Atas de Registro de Preços (ARP), para realizarem as solicitações de compras dos seus saldos registrados. 0 gráfico 4 demonstra a utilização dos sistemas para a realização de licitações.

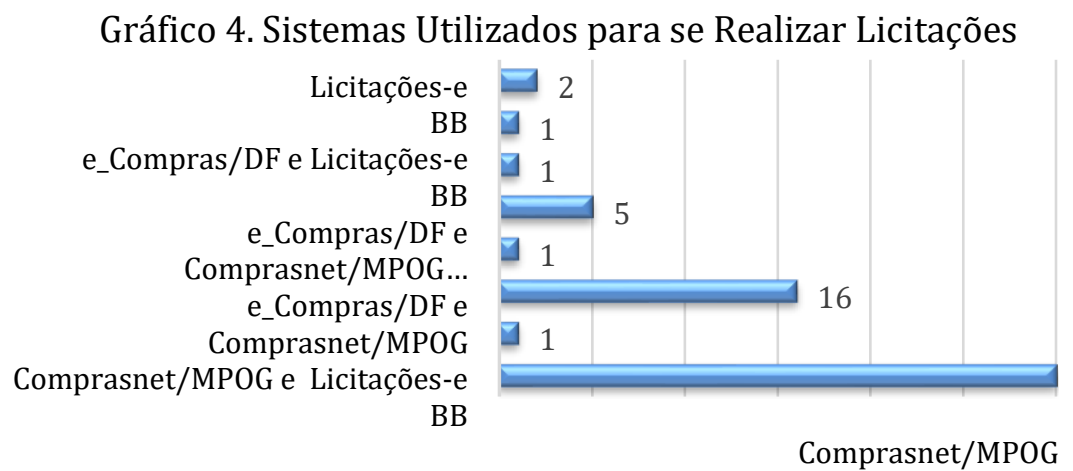

Portal de Compras da CEB Não possui Sistema Eletrônico30

$\begin{array}{lllllll}0 & 5 & 10 & 15 & 20 & 25 & 30\end{array}$

Fonte: Elaboração própria, com base nas planilhas de respostas do diagnóstico - COPLAM/SCG/SEPLAG.

O que se observa nas respostas é que quase metade dos órgãos da Administração Pública local utiliza o sistema do Banco do Brasil (e-Licitações) ou do Governo Federal (ComprasNet) para realizarem suas licitações. A utilização de múltiplos sistemas de compras tem como efeito uma menor transparência, além de dificultar a consolidação dos dados de fato licitados no Distrito Federal.

A maior parte dos órgãos informou que não possui em seus respectivos organogramas uma estrutura interna para realizar suas próprias licitações. Aqueles que possuem tais estruturas são basicamente as Entidades e os Órgãos Especiais, que possuem autonomia para suas licitações de cunho finalístico.

No que diz respeito à utilização do Sistema de Registro de Preços do Distrito Federal pelos órgãos, o resultado foi que $42,11 \%$ sempre usam e $35,09 \%$ às vezes utilizam. Comparativamente, com relação à participação nas licitações de Registro de Preços na esfera federal, foi observado que 5\% dos órgãos informam participar usualmente do SRP, e ainda que 60\% nunca participaram de licitação SRP nesta esfera. 
No que diz respeito à utilização do Sistema de Registro de Preços do Distrito Federal pelos órgãos, o resultado foi que $42,11 \%$ sempre usam e 35,09\% utilizam às vezes. Comparativamente, com relação à participação nas licitações de Registro de Preços na esfera federal, foi observado que 5\% dos órgãos informam participar usualmente do SRP, e ainda que 60\% nunca participaram de licitação SRP nesta esfera.

Os dados evidenciam que a centralização veio ao longo dos anos perdendo a capilaridade de atendimento. Dito de outro modo, a evidenciação de tal descentralização está fundamentalmente relacionada à utilização dos sistemas que reúnem e concentram as aquisições públicas, tais como: a Central de Compras e os demais sistemas informatizados utilizados pelos órgãos. Muitos fatores podem ser observados, como a falta da expansão do sistema para uso da Central e para os órgãos e a própria baixa institucionalização e modernização da área, que ocasionava baixa celeridade no atendimento dos processos, acarretando assim uma diminuição da centralização e um aumento de procedimentos descentralizados. Os resultados da pesquisa evidenciam que o modelo de compras praticado pela Administração Pública do Distrito Federal é um modelo de compras parcialmente centralizado, mas que possui características de descentralização. $\mathrm{Na}$ prática, $54 \%$ dos órgãos se autodeclaram descentralizados, ou seja, eles próprios se encarregam da realização das licitações. Isso significa que a autopercepção dos órgãos, captada pelo questionário aplicado, é que eles têm autonomia para realizar suas próprias aquisições.

No que diz respeito à utilização do sistema de registro de preços, o questionário mostrou que $77 \%$ dos órgãos do Distrito Federal participam das atas disponibilizadas pela Coordenação de Suprimentos da Subsecretaria de Compras Governamentais, os resultados demonstram que $42,11 \%$ dos órgãos sempre usam o SRP e 35,09\% às vezes utilizam.

No que diz respeito à utilização do sistema de registro de preços, o questionário mostrou que $77 \%$ dos órgãos do Distrito Federal participam das atas disponibilizadas pela Coordenação de Suprimentos da Subsecretaria de Compras Governamentais, os resultados demonstram que $42,11 \%$ dos órgãos sempre usam o SRP e 35,09\% utilizam às vezes.

Isso significa que o Sistema de Registro de Preços era o carro chefe das compras públicas no DF, o que caracterizava uma centralização, uma vez que a Subsecretaria fazia um esforço muito grande para manter centralizadas as aquisições de bens, materiais e serviços comuns que eram demandados por mais de um órgão, ou que eram oferecidos para vários órgãos.

Neste aspecto, o questionário mostrou que $77 \%$ dos órgãos afirmaram utilizar as atas de registro de preços que a Central disponibilizava. Como modo de chamar atenção dos órgãos, a Coordenação levantava os itens mais consumidos por estes, no ano anterior, e sugeria um plano de suprimentos para os órgãos que participavam de uma mesma licitação da central e depois empenhava seus itens à medida que havia a necessidade.

Dados demonstram que 43 dos 85 órgãos da Administração Pública local possuem decretos de descentralização de compras. Isto significa que $50 \%$ dos órgãos públicos do Distrito Federal estão autorizados a realizar licitações referentes a objetos específicos de sua pasta ou a atividades de cunho finalístico. Entretanto, com tal autorização, vários dos itens que são licitados nestes órgãos possuem registro vigente na Central de Compras. Do total de 72 decretos de descentralização de compras para os órgãos, 53\% foram publicados entre 2012 e 2013, indicando, assim, uma diminuição do escopo de atuação da Central de Compras do Distrito Federal no período.

No que se refere à utilização de sistemas para realização de procedimentos licitatórios, 27 órgãos dos 57 respondentes, isto é, $47 \%$ destes afirmaram que se utilizam de sistemas externos ao GDF, tais como: o ComprasNet (Governo Federal) e o Licitações-e (Banco do Brasil), em detrimento do e-Compras. Tal situação ilustra uma carência de padronização dos procedimentos relativos às compras públicas locais, além de evidenciar traços da descentralização existente.

Não obstante a isso, verificou-se grande diminuição dos valores licitados pelo sistema e-Compras, como diminuição dos atendimentos por atas de registro de preços, a falta de estrutura por parte dos órgãos em realizar suas licitações, identificando, assim, a necessidade por parte da central de prestar o serviço de centralização a estes órgãos.

Foi verificada, também, a falta de um sistema institucional do DF que atendesse às demandas, fazendo, assim, com que vários órgãos usem dois ou três sistemas diferentes. Ressalta-se que tal diversificação no uso de sistemas de compras acarreta custos de transparência e consolidação dos dados 
que são licitados no DF, dificultando a tomada de decisão e implantação de melhorias em todo o ciclo de compras.

Conforme assevera Ferrer (2015, p. 149), uma "inteligência centralizada de compras", certamente, permite uma visão única e inteligível do processo. Todavia, tal processo ainda esbarra na oportuna sinalização feita por Batista e Maldonado (2008), que salientaram acerca da arcaicidade que ainda se observa na estrutura da administração pública, a despeito de um mundo que exige continuamente maior dinâmica e flexibilidade, sobretudo, nas compras públicas cujo foco é fornecer o provisionamento necessário para que o poder público cumpra as suas obrigações e sirva à população da forma mais efetiva e abrangente possível.

\section{Implicações Teóricas e Práticas}

Este artigo se alinha aos estudos que ambicionam contribuir do ponto de vista teórico com a área de administração pública, especificamente no que concerne às compras públicas. Tal contribuição é feita na medida em que se desloca o foco de investigação para a efetividade do gasto público no âmbito subnacional. Sabe-se que a realidade fiscal dos estados brasileiros é de extrema vulnerabilidade econômica e déficit financeiro.

Acredita-se que a investigação dos modelos de compras adotados pelas unidades federativas, como é aqui empreendido, é uma oportunidade de se conhecer a política que os governos tem praticado no emprego do erário público e na racionalidade e efetividade das aquisições de bens e serviços. Conforme explicitado acima, Tridapalli (2008) evidencia a baixa adesão dos estados brasileiros a sistemas informatizados que conferem maior inteligibilidade e racionalidade das compras públicas.

Na prática, os dados, informações e a problematização do objeto de estudo deste trabalho poderão subsidiar decisões e ações de autoridades locais no que se refere à forma como estão sendo praticadas as compras públicas, seja para o simples fomentar do debate público, seja para o aprimoramento de modelos atuais ou, de forma mais ambiciosa, seja para inflexões que culminem em reorientações da política de aquisições públicas dos entes subnacionais.

\section{Considerações Finais}

Este estudo identificou, a partir da análise do modelo de compras praticado pela administração pública local, que o Governo do Distrito Federal adota um modelo de compras parcialmente centralizado, mas que possui características de descentralização. Contudo, ainda é necessária uma redefinição dos processos e procedimentos, que, por sua vez, devem estar embasados no uso de sistemas integrados para execução e gerenciamento do ciclo completo das compras, desde o planejamento, padronização dos procedimentos, levantamento da demanda, identificando o ponto de ressuprimento, acompanhamento contratual até a identificação dos resultados alcançados.

Ressalta-se que o modelo de compras parcialmente centralizado do GDF pode ser consolidado por meio da concentração do Sistema de Registro de Preços no órgão central de planejamento, buscando, assim, maior atendimento das demandas e ainda evitando duplicidade de atribuições em diversas estruturas dos outros dos órgãos da administração pública (Ferrer, 2015; Raposo et. al., 2016).

Evidentemente que o caráter descritivo deste trabalho, baseado em estudo de caso, não permite generalizações. Mas uma futura agenda de pesquisa seria a investigação sobre como ocorrem as compras governamentais em outros Estados e municípios, de forma a se obter informações comparáveis e se formular hipóteses robustas sobre o funcionamento de tais centrais ou sistemas de compras, inclusive para futuras recomendações de melhorias processuais e normativas.

Em tempo de mudanças rápidas e significativas marcadas pelo advento das novas tecnologias, governança de dados, inteligência artificial, a administração pública tem a oportunidade de rever seus modelos de gestão. Outrossim, cabe ao gestor de compras buscar ou assumir o papel empreendedor em um cenário em constante mudanças tecnológicas que impactam decisivamente a forma de obter serviços, realizar transações etc.

Com isso, futuras pesquisas podem ampliar o foco de investigação abordado neste trabalho e apontar caminhos para o redesenho do modelo descentralizado de compras, como é atualmente realizado no Distrito Federal, mas que promova a governança das aquisições como órgão central na gestão dos dados, na padronização dos procedimentos, na capacitação contínua e efetiva dos agentes de compras, na disponibilização de um único sistema que melhore o cruzamento dos dados, na troca de 
informações, na colaboração entre os órgãos, promovendo melhores entregas à sociedade.

\section{Referências Bibliográficas}

Batista, M. A. C., \& Maldonado, J. M. S. V. (2008). O papel do comprador no processo de compras em instituições públicas de ciência e tecnologia em saúde (C\&T/S). Revista de Administração Pública, 42(4), p. 681-699.

Bleda, M., \& Chicot, J. (2020). The role of public procurement in the formation of markets for innovation. Journal of Business Research, 107, p. 186-196.

Cartaxo, F., \& Marini, C. (2010). Gestão da despesa pública e da accountability financeira. Congresso CONSAD de Gestão Pública, Brasília.

Decreto $n^{\circ}$ 7.892, de 23 de janeiro de 2013. (2013). Diário Oficial da República Federativa do Brasil, Brasília, 24 de janeiro de 2013.

Decreto $n^{\circ}$ 39.610, de 1ํ de janeiro de 2019. (2019). Dispõe sobre a organização da estrutura da Administração Pública do Distrito Federal. Publicado no DODF no 1, Edição Extra Especial, seção 1 e 2 de 01/01/2019.

Delzot, A. L. P., \& Barbosa, G. P. (2017). Desafios e perspectivas para a comparação do desempenho de compras dos estados e suas boas práticas: a proposta de um meta-modelo de avaliação. Congresso CONSAD de Gestão Pública, Brasília.

Ferrer, F. (2015). Diagnóstico da situação das compras públicas no Brasil. In F. Ferrer, J. E. Santana (Coords.). Compras Públicas Brasil. Rio de Janeiro: Elsevier.

Ferrer, F. (2013). Os desafios do setor público para construir um novo modelo de Compras. Congresso CONSAD de Gestão Pública, Brasília.

Fernandes, C. C. C. (2015). A centralização das compras na administração federal: lições da história. Brasília: VIII Congresso CONSAD de Gestão Pública, Painel 48/148.

Fiuza, E. P. S., \& Medeiros, B. A. (2013). A Reforma da Lei 8.666/93 e do arcabouço legal de compras públicas no Brasil: contribuições do Ipea à Consulta Pública do Senado. Brasília: Nota Técnica para o Instituto de Pesquisa Econômica Aplicada. IPEA, 2013. Recuperado em 15 de agosto de 2017, de http://repositorio.ipea.gov.br/handle/11058/5766

Harland, C., Telgen, J., Callender, G., Grimm, R., \& Patrucco, A. (2019). Implementing Government Policy in Supply Chains: An International Coproduction Study of Public Procurement. Journal of Supply Chain Management, 55(2), p. 6-25.

Lei no 8.666, de 21 de junho de 1993. (1993). Diário Oficial da República Federativa do Brasil, Brasília, de 22 de junho de 1993.

Miguel, L. F. H. (2015). Licitação: passado, presente e futuro. Fórum de Contratação e Gestão Pública, 14(158), p. 41-49.

Moreira, E. B., \& Ribeiro, L. C. (2016). Centralização de compras públicas no Brasil. Revista de Direito Público da Economia, 14(56), p. 57-74.

Organização para a Cooperação e Desenvolvimento Econômico - OCDE. (2016). Public procurement, oecd.org.

Portaria $n^{\circ}$ 563, de 5 de setembro de 2002. (2002). Altera o Anexo Único à Portaria SEFP no 648 de 21 de dezembro de 2001, e dá outras providências. Publicado no Diário oficial do Distrito Federal em 10 de setembro de 2009.

Raposo, M. H., Freitas, M.S., \& Silva Filho, M.T.; Fernandes, M. S. B.; Silva, R. L. A importância do planejamento de compras para a gestão estratégica de suprimentos. In: Congresso CONSAD de Gestão Pública, Brasília, 2016.

Ribeiro, C. G., \& Inácio Júnior, E. (2019). O Mercado de compras governamentais brasileiro (2006-2017): mensuração e análise. Texto para Discussão Ipea, 2476, p. 1-38.

Secretaria da Fazenda do distrito Federal. Subsecretaria de Contabilidade. Balanço Geral 2016. Recuperado em 25 de agosto de 2017, de http://www.transparencia.df.gov.br/arquivos/RLG \%202016\%20BALANÇ0\%20GERAL.pdf

Secretaria da Fazenda do distrito Federal. Subsecretaria de Compras e Licitações. Relatório de Atividades - 2005. (Não publicado).

Secretaria da Fazenda do distrito Federal. Subsecretaria de Compras e Licitações. Relatório de Atividades - 2006. (Não publicado). 
Secretaria da Fazenda do distrito Federal. Subsecretaria de Compras e Licitações. Relatório de Atividades - 2007. (Não publicado).

Secretaria da Fazenda do distrito Federal. Subsecretaria de Compras e Licitações. Relatório de Atividades - 2008. (Não publicado).

Secretaria da Fazenda do distrito Federal. Subsecretaria de Compras e Licitações. Relatório de Atividades - 2009. (Não publicado).

Secretaria de Planejamento, Orçamento e Gestão do Distrito Federal. Subsecretaria de Compras Governamentais. Relatório Gerencial 2016.

Silva, R. L. (2016). Compras centralizadas e descentralizadas: estudo de caso sobre os impactos de um modelo híbrido de compras na obtenção de gêneros alimentícios pela Marinha do Brasil. Dissertação de Mestrado. Pontifícia Universidade Católica do Rio de Janeiro.

Thai, K.V. (2001). Public Procurement Re-examined. Journal of Public Procurement, 1(1), p. 9-50. Tridapalli, J. P., Fernandes, E., \& Machado, W. V. (2011). Gestão da cadeia de suprimentos do setor público: uma alternativa para controle de gastos correntes no Brasil. Revista de Administração Pública, 45(2), 401-433.

Tridapalli, J. P. (2008). Comércio Eletrônico: Uma perspectiva no setor público para melhoria da logística. Tese (Doutorado em Engenharia de Transportes). Universidade Federal do Rio de Janeiro, Rio de Janeiro.

Vergara, S. C. (2008). Projetos e relatórios de pesquisa em Administração. São Paulo: Atlas.

Zylberman, M. (2015). A gestão das compras públicas dos Estados brasileiros: a experiência do Rio de Janeiro com a opção da descentralização. Dissertação (Mestrado em Administração Pública). Fundação Getúlio Vargas, Rio de Janeiro. 